\title{
Hormonal control of a carbohydrate epitope involved in implantation in mice
}

\author{
S. J. Kimber* and S. Lindenberg $\dagger$ \\ *Department of Cell and Structural Biology, University of Manchester, Coupland III Building, \\ Coupland St, Manchester M13 9PL,UK; *MRC Experimental Embryology and \\ Teratology Unit, St George's Hospital Medical School, London SW17 ORE, UK; \\ and $\dagger$ Department of Obstetrics/Gynaecology, Rigshospitalet, University of Copenhagen, \\ Blegdamsvej 9, 2100 Copenhagen, Denmark
}

\begin{abstract}
Summary. Ovariectomy and hormone replacement of mice were used to examine the hormonal control of expression on the uterine surface of a carbohydrate determinant (lacto-N-fucopentaose I, LNF I), involved in the initial interaction between the blastocyst and the endometrial epithelium at implantation. Pseudopregnant mice mated with sterile males were also used to elucidate the impact of embryonic signals on the expression of this antigen on the uterine surface. Two groups of fucosylated structures could be distinguished; one group was predominantly dependent on maternal oestrogen and progesterone, while the other group appeared to be less influenced by the hormonal milieu.
\end{abstract}

Keywords: implantation; uterus; hormones; carbohydrates; receptors; mouse

\section{Introduction}

It is well established that implantation of the mammalian blastocyst is controlled by steroid hormones (Finn \& Martin, 1974; Psychoyos \& Casimiri, 1980) which act to determine the receptivity of the uterus for the embryo. However, until recently (Armant et al., 1986a, b; Farach et al., 1987; Kimber et al., 1988; Lindenberg et al., 1988; Sutherland et al., 1988) there has been little evidence as to the identity of the molecules involved in this process. Preparation of the uterus for the blastocyst requires a period of exposure to low levels of progesterone followed by a nidatory pulse of oestrogen (Psychoyos, 1976). There is a specific 'window' during which the uterus can respond to embryonic signals, leading to decidualization, attachment and implantation of the blastocyst (McLaren \& Michie, 1956; Psychoyos \& Casimiri, 1980; Leroy, 1982; Psychoyos, 1986). We have previously shown that a specific carbohydrate determinant, LNF-I (lacto-N-fucopentaose I) present on the surface of the uterus is involved in the initial attachment of the blastocyst to the uterine epithelium (Lindenberg et al., 1988). One would therefore predict that such a determinant will be under hormonal control. Indeed, oestrogens have been shown to stimulate the synthesis of certain glycoproteins to a greater extent than others in the rabbit (Anderson et al., 1986), the rat (Kuivanen \& DeSombre, 1985) and the mouse (Teng et al., 1986; Pentecost \& Teng, 1987). Therefore, in this study we describe the influence of the hormonal environment on the expression of LNF-I, and other carbohydrate structures known to be present on the endometrial epithelium, by using ovariectomy and hormone replacement.

A considerable amount of evidence suggests that embryonic signals are important for uterine receptivity (Fishel \& Surani, 1980; Kennedy, 1983; Nieder et al., 1987). This study therefore also includes an investigation of these carbohydrate epitopes in pseudopregnant mice to ascertain whether the presence of the embryo influences their expression. 


\section{Materials and Methods}

Animals. The mice were B6D2F1/BOM F1 hybrids (from the Laboratory of Animal Breeding and Research Center, Gl. Bomholdt Grd, Ltd, 8680 Ry, Denmark) and B6CB/F1 hybrids (from the MRC Laboratories Carshalton, Surrey, UK), and sterile T145 males (Lyon \& Meredith, 1966; also from MRC Laboratories Carshalton).

Ovariectomy and hormone replacement. Female mice weighing $20-25 \mathrm{~g}$ were mated with males of the same strain and checked each morning for formation of a vaginal plug. The day of plug formation was designated Day 1 of pregnancy. Bilateral ovariectomy was performed before 12:00 h on Day 3 of pregnancy under pentobarbitone sodium anaesthesia and $1.5 \mathrm{mg}$ progesterone (Depo-Provera, Upjohn, Puurs, Belgium), 0.05 $\mathrm{g}$ gestradiol benzoate (Sigma, Poole, Dorset, UK) in corn oil, or the vehicle only was administered. This injection regimen was repeated on Day 6 of pregnancy. On Day 11 of pregnancy delay the animals were treated in one of four ways: they were intraperitoneally injected with: (a) $1.5 \mathrm{mg}$ progesterone only (P); (b) $1.5 \mathrm{mg}$ progesterone $+0.05 \mu \mathrm{g}$ oestradiol benzoate in corn oil ( $\mathrm{P}+$ E); (c) $0.05 \mu \mathrm{g}$ oestradiol benzoate in corn oil without progesterone (E); (d) $1.5 \mathrm{mg}$ progesterone and corn oil without oestradiol. The animals were killed 12,18,24 or $48 \mathrm{~h}$ after the final injection and the uterine horns were snap frozen in isopentane cooled on solid $\mathrm{CO}_{2}$. Horns from 5-12 animals were examined for each regimen and time point.

Pseudopregnant mice. Sterile homozygous T145 males (Lyon \& Meredith, 1966) were caged with female B6D2F1/ BOM mice. Alternatively, vasectomized males of the strain B6CB Fl of proven infertility were caged with B6CB F1 females. The day of plug formation was designated Day 1 of pseudopregnancy. Females were killed on Day 1, 2, 3, 4, $5,6,7$ or 8 of pseudopregnancy and the uterine horns were snap frozen as described above. Horns from 4-6 animals were used for each day of pseudopregnancy.

Monoclonal antibodies. Mouse monoclonal antibodies (IgM) (Table 1) with known carbohydrate specificity were provided as supernatants with an approximate concentration of $100 \mu \mathrm{g}$ immunoglobulin/ml by BioCarb AB (Lund, Sweden). Supernatants containing the antibodies 667/9E9, H004, 630/7HI (Monocarb product information, Monocarb catalogue No. 1: MonoCarb AB, S-223-70, Lund, Sweden), HOO1 (Endblad et al., 1986; Brodin et al., 1987), Le-b (Messeter et al., 1984) and A003 (Chen \& Kabat, 1985) were used to stain frozen sections of mouse uterus in a double-layer technique using a FITC-labelled second antibody as previously described (Kimber et al., 1988). Stained sections were viewed using a Zeiss epi-fluorescence microscope with a mercury source for illumination and excitation filter BP 450-490 and suppression filter LP 515, and photographed.

Table 1. Murine monoclonal antibodies used to detect oligosaccharide determinants on epithelial monolayers and blastocysts or in the implantation inhibition studies

\begin{tabular}{|c|c|c|c|}
\hline Code & Isotype & & Specificity \\
\hline $667 / 9 \mathrm{E} 9$ & $\operatorname{IgM}$ & LNF I & Fuc $\alpha$ l-2Gal $\beta 1-3$ GlcNAc \\
\hline $630 / 7 \mathrm{H} 1$ & IgM & LNF III & Gal $\beta 1-4($ Fuc $\alpha 1-3)$ GleNAc \\
\hline $\mathrm{H} 001$ & IgM & LND I LNneoD I* & Fuc $\alpha 1-2$ Gal $\beta 1-3 / 4($ Fuc $\alpha 1-3 / 4)$ GlcNAc \\
\hline H004 & IgM & $\begin{array}{l}\text { LNneoD I* } \\
\text { LNneoF I } †\end{array}$ & $\begin{array}{l}\text { Fuc } \alpha 1-2 \text { Gal } \beta 1-4( \pm \text { Fuc } \alpha 1-3) 1- \\
\text { 4GlcNAc }\end{array}$ \\
\hline Leb & IgM & LND I & Fuc $\alpha 1-2$ Gal $\beta 1-3$ (Fuc $\alpha$ 1-4)GlcNAc \\
\hline A003 & IgM & A trisaccharide & GalNAc $\alpha 1-3($ Fuc $\alpha 1-2) \mathrm{Gal}$ \\
\hline
\end{tabular}

*Lacto-N-neo-difuco-hexaose I.

t Lacto-N-neo-fuco-pentaose I.

\section{Results}

\section{Ovariectomized mice}

Table 2 summarizes the results of staining frozen sections of uterus from ovariectomized mice with 5 monoclonal antibodies recognizing carbohydrate structures (Table 1) known to be present on the endometrial epithelium in early pregnancy. In Table 2 the overall staining pattern of the luminal epithelium is recorded. As reported previously (Kimber et al., 1988) none of the antibodies used bound to stromal tissue irrespective of the hormone replacement regimen to which the animal 
Table 2. Staining of the apical luminal endometrial epithelium of B6D2/

Bom F1 mice after ovariectomy and hormone replacement

\begin{tabular}{|c|c|c|c|c|c|c|}
\hline \multirow{2}{*}{$\begin{array}{l}\text { Hormone } \\
\text { treatment }\end{array}$} & \multicolumn{6}{|c|}{ Antibodies } \\
\hline & $667 / 9 \mathrm{E} 9$ & $630 / 7 \mathrm{HI}$ & H001 & H004 & Le-b & A003 \\
\hline \multicolumn{7}{|l|}{ Day 5 of } \\
\hline $\mathrm{EEE}+12$ & ++ & ++ & ++ & ++ & ++ & - \\
\hline $\mathrm{EEE}+18$ & ++ & $+t$ & +++ & +++ & ++ & - \\
\hline $\mathrm{EEE}+24$ & ++ & + & \pm & $+t$ & ++ & - \\
\hline PPE + 18 & +++ & +++ & +++ & +++ & ++ & - \\
\hline$P P P+12$ & - & + & - & + & + & - \\
\hline$P P P+18$ & - & ++ & + & ++ & - & - \\
\hline$P P P+24$ & - & + & - & - & - & - \\
\hline$P P(P+E)+12$ & ++ & ++ & ++ & ++ & - & - \\
\hline$P P(P+E)+18$ & ++ & +++ & ++ & $++t$ & ++ & - \\
\hline$P P(P+E)+24$ & + & ++ & +++ & +++ & ++ & - \\
\hline$P P(P+E)+48$ & ++ & ++ & +++ & +++ & + & - \\
\hline $\mathrm{PP}-+0$ & - & $+t$ & + & \pm & - & - \\
\hline Vehicle & - & + & - & - & - & - \\
\hline
\end{tabular}

$\mathrm{E}=$ oestradiol benzoate; $\mathrm{P}=$ progesterone; $12,18,24,48=$ hours.

had been subjected. Antibody A003 acted as a negative control. This antibody did not stain uterine tissue of mice in delayed implantation or pregnancy.

\section{Antibody 667/9E9}

The luminal and glandular endometrial epithelia were stained with Antibody 667/9E9 only after injection of oestrogen with or without progesterone (Fig. 1). When both oestrogen and progesterone were given, all surfaces and cytoplasm of reactive cells were stained (Fig. Ib). In contrast, after oestrogen alone the basal and lateral surfaces of the cells were almost unstained while the luminal aspects of the cells reacted with the antibody (Fig. 1c). A punctate pattern of fluorescence was observed at the surfaces of the cells and areas positive for the antibody were present in patches between stretches of cells lacking reactivity. Fluorescence from the secretions in glands and lumen was variable. After ovariectomy in the absence of hormone replacement, Antibody 667/9E9 did not react with glandular or luminal epithelia.

\section{Antibody 630/7H1}

This antibody reacted intensely with the apical surfaces of luminal endometrial epithelial cells, whether the ovariectomized females had been injected with progesterone + oestrogen or oestrogen alone (Figs $2 b \& 2 c$ ). However, there was a slight reduction in the intensity of staining when progesterone alone was injected (Fig. 2a), and some reduction in staining of lateral and basal surfaces and cytoplasm after oestrogen alone (Fig. 2c). In the absence of hormone replacement a low to moderate level of staining of the epithelium with Antibody $630 / 7 \mathrm{H} 1$ was still observed. The glands, in contrast, bound the antibody weakly although slightly greater binding was observed in the presence of oestrogen.

\section{Antibodies H001 and $\mathrm{H004}$}

After progesterone + oestrogen or oestrogen alone the luminal and glandular epithelium also bound large amounts of antibodies $\mathrm{H} 001$ and $\mathrm{H} 004$ (Figs $3 b_{\text {\& }} 3 \mathrm{c}$ ). Staining was slightly greater on: 03:28AM 

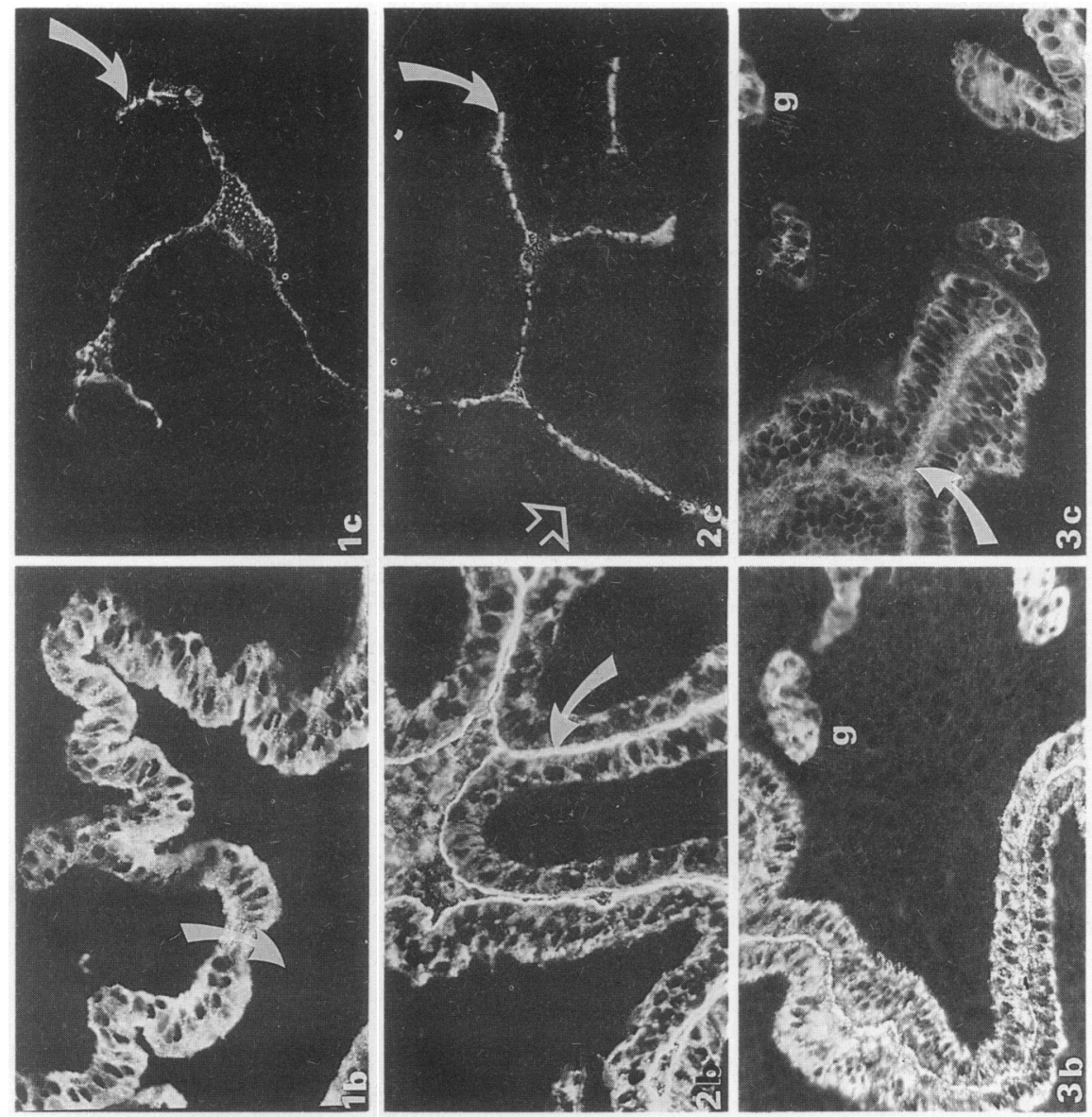

家

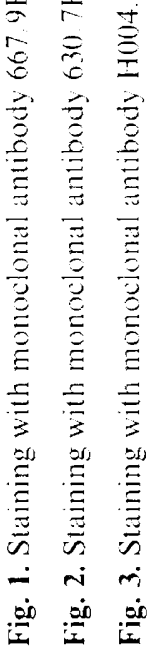
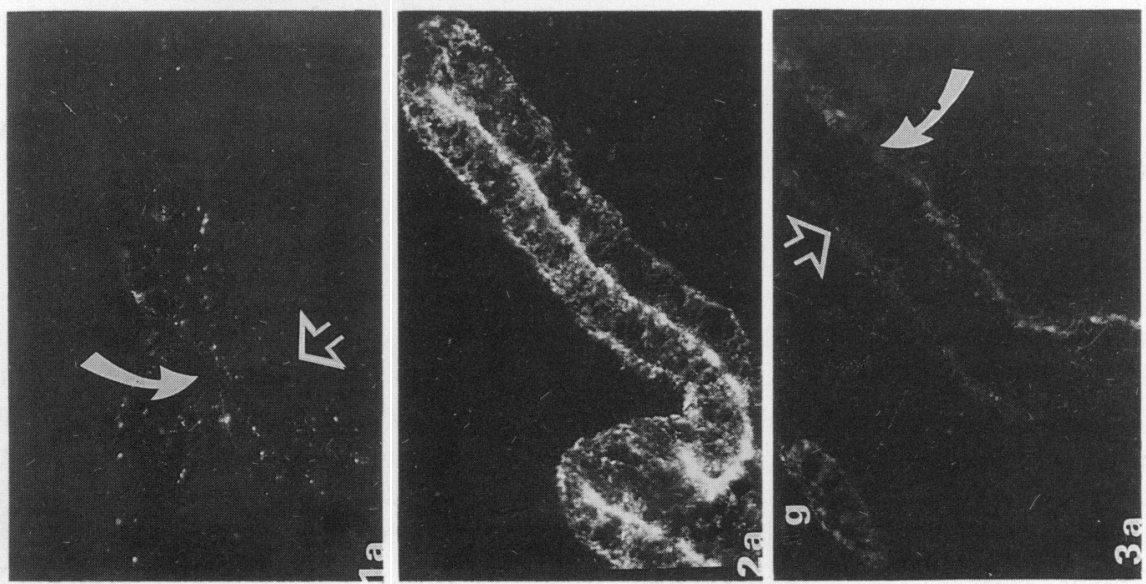


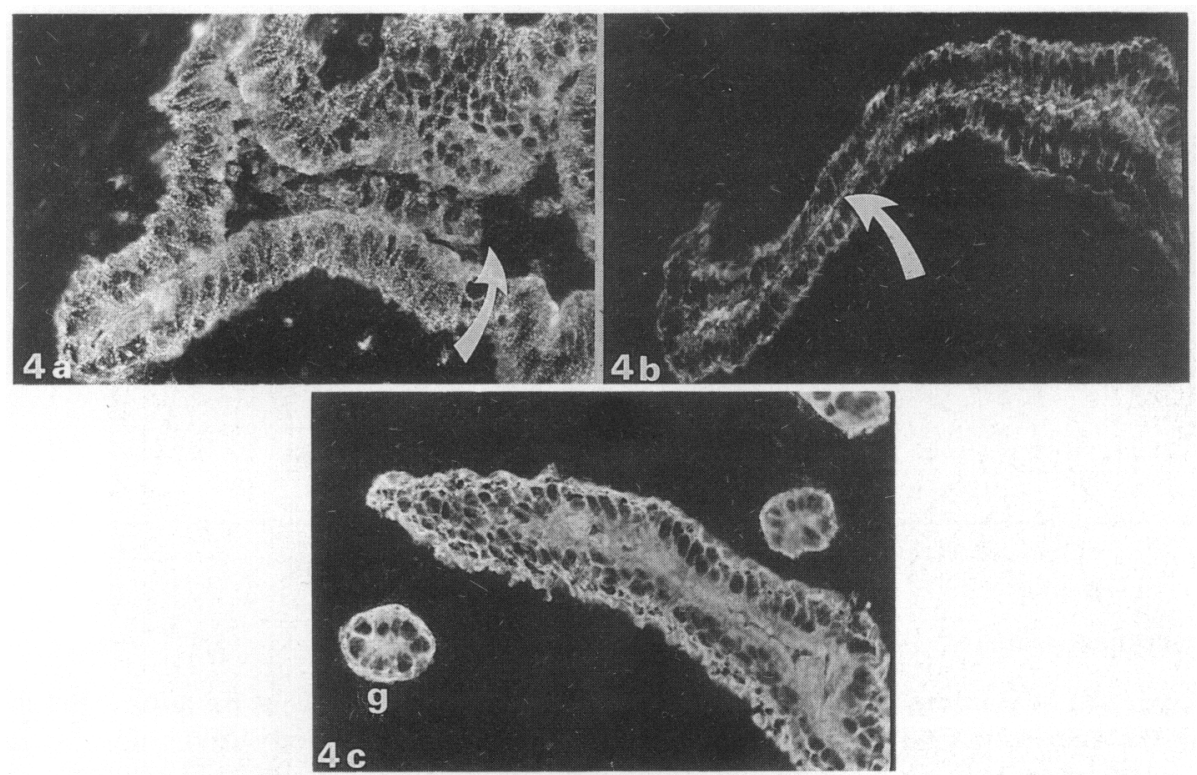

Fig. 4. B6CB Fl female mated with T145 (sterile) male, and killed on Day 4 of pseudopregnancy: uterus stained with (a) Antibody 667/9E9, (b) Antibody 630/7H1, (c) Antibody H004.

\begin{abstract}
All figures show staining of frozen sections through the luminal epithelium of the mouse uterus with monoclonal antibodies recognizing various carbohydrate antigens. In some cases glands (g) can also be observed in the micrographs. Hormone treatments were carried out as described in 'Materials and Methods'. Closed arrows, luminal aspect of epithelium; open arrows, basal surface of epithelium. For Figs 1-3, (a) ovariectomized female treated with progesterone only and examined $18 \mathrm{~h}$ after the final progesterone injection; (b) ovariectomized female treated with progesterone and oestrogen and examined $24 \mathrm{~h}$ after the final injection; (c) ovariectomized female treated with oestrogen only and examined $12 \mathrm{~h}$ after the final injection.
\end{abstract}

the luminal epithelium than on the glands, particularly on the apical aspects of these cells. The secretions in glands and lumen were stained with variable intensity. At $24 \mathrm{~h}$ after a final injection of oestrogen alone Antibody H001 staining was extremely weak, in contrast to the strong staining at a similar time after progesterone + oestrogen.

There was some variability in the staining with Antibodies $\mathrm{H} 001$ and H004, particularly after progesterone alone: $\mathrm{H} 00 \mathrm{I}$ and $\mathrm{H} 004$ stained the luminal epithelium $18 \mathrm{~h}$ after progesterone treatment alone, but $24 \mathrm{~h}$ after the hormone treatment no staining was observed (Fig. $3 \mathrm{a}$ ).

\title{
Antibody Le-b
}

The antibody recognizing the Le-b epitope did not react with the uterine epithelium of females treated with progesterone alone, although a low level of binding to the luminal epithelium was observed $12 \mathrm{~h}$ after a final injection of the hormone. Animals injected with corn oil and progesterone were indistinguishable from those injected only with progesterone. After ovariectomy without hormone replacement or injection of corn oil alone, the uterine epithelium did not bind this antibody. Although, at $12 \mathrm{~h}$ after a final injection of both oestrogen and progesterone there was an absence of staining, considerable amounts of antibody bound to the epithelium 18 and $24 \mathrm{~h}$ after administration of the hormones. When oestrogen alone was given as the final injection after progesterone $($ PPE +18$)$ or oestrogen $(E E E+12-24)$, the Le-b determinant could also be detected on the epithelium. 
Table 3. Amalgamated data for staining of uteri from pseudopregnant F1 females (PSP) mated either with T145 sterile males or vasectomized B6D2/F1 males and results from normal pregnant animals

\begin{tabular}{|c|c|c|c|c|c|c|c|c|c|c|c|c|}
\hline \multirow[b]{3}{*}{ Day* } & \multicolumn{12}{|c|}{ Antibodies } \\
\hline & \multicolumn{2}{|c|}{$667 / 9 \mathrm{E} 9$} & \multicolumn{2}{|c|}{$630 / 7 \mathrm{H} 1$} & \multicolumn{2}{|c|}{ H00I } & \multicolumn{2}{|c|}{ H004 } & \multicolumn{2}{|c|}{$\mathrm{A} 003$} & \multicolumn{2}{|c|}{ Le-b } \\
\hline & $\mathbf{P}$ & PSP & $\mathbf{P}$ & PSP & $\mathbf{P}$ & PSP & $\mathbf{P}$ & PSP & $\mathrm{P}$ & PSP & $\mathrm{P}$ & PSP \\
\hline 1 & ++ & ++ & + & ++ & + & $++t$ & + & $++t$ & - & - & + & $t+$ \\
\hline 3 & ++ & ++ & ++ & +++ & +++ & +++ & +++ & +++ & - & - & + & ++ \\
\hline 4 & + & ++ & ++ & ++ & +++ & +++ & +++ & +++ & - & - & + & + \\
\hline 5 & \pm & + & + & ++ & ++ & +++ & ++ & +++ & - & - & \pm & + \\
\hline 6 & \pm & + & + & +++ & + & +++ & + & +++ & - & - & - & \pm \\
\hline 7 & \pm & - & \pm & ++ & + & ++ & ++ & ++ & - & - & - & - \\
\hline 8 & - & - & ++ & + & + & + & + & + & - & - & - & ++ \\
\hline
\end{tabular}

*Of pregnancy or pseudopregnancy.

\section{Pseudopregnant animals}

The pattern of staining found on the uterine epithelium and glands of pseudopregnant female mice on the days following mating is shown in Table 3. Again Antibody A003 did not stain any uterine tissue. Staining with Antibody 667/9E9 on the endometrial epithelium was high until Day 3 or 4 of pseudopregnancy, but by Day 5 staining was much reduced in the D2B2/Bom F1 females mated with sterile T145 males, and similar to that found for pregnant animals (Fig. 4a). In the $\mathrm{B} 6 \mathrm{CB} / \mathrm{F} 1$ females mated with vasectomized males of their own strain, staining with Antibody $667 /$ 9E9 remained higher until Day 6 after which it decreased to negligible levels. By Day 7 or 8 of pseudopregnancy no staining could be detected with this antibody.

Antibody Le-b showed a similar pattern of fluorescence to $667 / 9 \mathrm{E} 9$ with near absence of antibody binding by Day 6 of pseudopregnancy in the D2B2/Bom F1 females. This paralleled the changes observed in pregnant females (Table 3 ).

Staining remained detectable with Antibodies $\mathrm{H} 001$, H004 and 630/7H1 (Figs 4b \& 4c) at all stages up to Day 7 and 8 of pseudopregnancy. In pregnant mice binding of Antibodies $630 / 7 \mathrm{H} 1$ and $\mathrm{H} 001$ remained high at least until Day $4 / 5$, but then decreased to a low level by Day 7 .

\section{Discussion}

It has often been demonstrated, using the regimen of ovariectomy and hormone replacement employed in this study, that blastocysts undergo delay of implantation during the phase of progesterone dominance but are reactivated to implant upon injection of oestrogen (Finn \& Martin, 1974; Chavez \& Anderson, 1985). The normal events leading up to implantation are therefore promoted by a rise in oestrogen. It has also been observed that the progesterone to oestrogen ratio is critical for successful pregnancy (Psychoyos, 1976; Gidley-Baird et al., 1986).

In this paper we report that a carbohydrate determinant, lacto-N-fucopentaose I (LNF I), on the endometrial epithelium appears only after oestrogen injection, and not after injection of progesterone alone. This determinant has been shown previously to be involved in attachment of the blastocyst to uterine epithelial cells (Lindenberg et al., 1988). Moreover, in naturally mated mice this determinant is expressed at high levels on the first $1-4$ days of pregnancy, presumably under the influence of oestrogen, but between Days 4 and 5 of pregnancy becomes restricted to stretches of cells interspersed with unstained cells (Kimber et al., 1988). In this study a similar change was observed after injection of ovariectomized mice with oestrogen and progesterone although we did not notice a significant decline in antibody staining even after $48 \mathrm{~h}$ from oestrogen injection. This

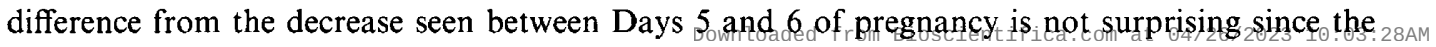


nidatory peak of oestrogen is reached on Day 3 of pregnancy. After $48 \mathrm{~h}$, on Day 5 , receptors for Antibody $667 / 9 \mathrm{E} 9$ are still present on the luminal epithelium, although the antibody binding is reduced. After injection of oestrogen alone only the apical luminal staining was high as shown in the table and this pattern of predominantly apical staining resembled that found in the non-pregnant female (Fig. 2a; Kimber et al., 1988). This reflects the resemblance of the oestrogen-dominated uterus of the ovariectomized mouse to that of the non-pregnant hormonal state.

Antibody 667/9E9 is known to recognize $\mathbf{H}$ type- 1 blood group-related structures. The antibody Le-b also recognizes type-1 chains whereas Antibodies $630 / 7 \mathrm{H1}$ and $\mathrm{H} 004$ only recognize type- 2 chains, and Antibody $\mathrm{H} 001$ recognizes structures of types 1 and 2 . Tables 2 and 3 demonstrate differences in staining pattern between antibodies recognizing type-1 structures only and type- 2 structures only. In delayed implantation mice progesterone briefly induces the appearance of a peak of type- 2 chains on the surface of glands and epithelium around $18 \mathrm{~h}$ after injection. In contrast, oestrogen administration induces a persistently high level of staining, only decreasing $24 \mathrm{~h}$ after injection for Antibody H001, and possibly slightily for Antibody 630/7H1. In general, the maximum overall staining for all the antibodies was observed $18-24 \mathrm{~h}$ after a final injection of progesterone + oestrogen or oestrogen alone after earlier progesterone injections, a regimen which most accurately mimics the hormonal environment just before implantation (McCormack \& Greenwald, 1974; Barkley et al., 1979). This suggests not only that the presence of a progesteronedominated uterus followed by a 'nidatory' peak of oestrogen stimulates maximum expression of these type- 1 and -2 oligosaccharides, but also that the combination of these two hormones leads to the optimum conditions for their expression.

The Le-b antibody showed greater binding to the luminal epithelium after injection of oestrogen than after progesterone injection. It follows the pattern of staining observed with Antibody $667 / 9 \mathrm{E} 9$ with respect to the response to progesterone or oestrogen alone, but after injection of both progesterone and oestrogen it appeared more slowly; only after $18 \mathrm{~h}$. This may indicate that the oligosaccharide determinants recognized are present on separate carbohydrate chains or at least are differentially controlled.

Although observation of the pattern of staining in the pseudopregnant uterus suggests subtle changes from the pregnant uterus, these were not sufficient for us to be able to conclude that the embryo has a significant effect on antigen expression. Several recent studies have provided biochemical evidence for major changes in the uterine glycoproteins of rodents during the pre- and peri-implantational phases (Kuivanen \& DeSombre, 1985; Anderson et al., 1986; Dutt et al., 1987; Teng et al., 1986; Morris et al., 1988; Takeda et al., 1988). However, we have approached this problem from the opposite direction of an already detected function, and shown that the H-type 1 carbohydrate structure involved in attachment of the blastocyst appears in an oestrogen-dependent fashion on the endometrial epithelium. Expression of some other carbohydrate structures (with as yet unknown roles) on the endometrial epithelium also appears to be hormone-dependent.

Our finding that fucosylated type-2, Galß1-4GlcNAc-containing determinants are present on the endometrium is at variance with the conclusion of Dutt et al. (1988) that uterine lactosaminoglycans are not substituted with fucose. Their conclusion was based on lectin binding and metabolic incorporation of $\left[{ }^{3} \mathrm{H}\right\}$ fucose by uterine tissue slices. However, Fox et al. (1981) also reported staining of the endometrial lining of the uterus with SSEA-1. This antibody binds the Gal $\beta 1-4$ (Fuc 1-3) GlcNAc determinant also recognized by Antibody $630 / 7 \mathrm{H} 1$, and present on the fucosylated lactosaminoglycans of embryonic tissues (Muramatsu et al., 1978, 1983; Solter \& Knowles, 1978; Pennington et al., 1985). Babiarz \& Hathaway (1988) demonstrated immunocytochemically that the SSEA-1 determinant is expressed on the uterine epithelium in the presence of both oestrogen and progesterone. Sialylated branched and linear (type-2 chain) lactosaminoglycans also appear on the uterine epithelium under the control of these hormones. However, in that study the effect of progesterone alone was not assessed and the injection regimen would not accurately mimic the normal dynamic hormonal changes experienced by the uterus in vivo (McCormack \& Greenwald, 
1974; Barkley et al., 1979). From the present and previous (Kimber et al., 1988) studies we conclude that fucose-containing type-1 and type- 2 chains are expressed on the mouse endometrial epithelium under hormonal control. In the absence of hormone replacement after ovariectomy we could not demonstrate the presence of any of the antigens investigated except for low levels of the SSEA-1 determinant, recognized by Antibody 630/7H1.

The major group of glycoproteins reported by Dutt $e t$ al. (1988) to be stimulated by oestrogen in the mouse uterus were unfucosylated (type 2) lactosaminoglycans while in this study we observed oestrogen stimulation of fucosylated type-2 chains (recognized by Antibodies $\mathrm{H} 004$ and 630/7H1). The discrepancy between these results may be explained by the differences in the methods used to investigate these structures. The data of Dutt et al. (1988) correspond to whole uterine tissue and minority components present only on the cell surface and in secreted material from the epithelial cells would not be detected.

We thank Helle Henriksen, Natasha Warren and Thomas Andersson for dedicated and skilled technical assistance. This work was supported by grants from Biocarb AB, the Nuffield Foundation, the Danish Medical Research Council, the Brandt Brandtved Foundation and the Haench Foundation.

\section{References}

Anderson, T.L., Olsen, G.E. \& Hofiman, L.H. (1986) Stage specific alterations in the apicai membrane glycoproteins on endometrial epithelial cells related to implantation in rabbits. Biol. Reprod. 34, 701-720.

Armant, D.R., Kaplan, H.A. \& Lennarz, W.I. (1986a) Fibronectin and laminin promote in vitro attachment and outgrowth of mouse blastocysts. J. Cell Biol. $116,419-423$.

Armant, D.R., Kaplan, H.A., Mover, H. \& Lennarz, W.I. (1986b) The effect of hexapeptide on attachment and outgrowth of mouse blastocysts cultured in vitro: evidence for the involvement of the cell recognition tripeptide Arg-Gly-Asp. Proc. natn. Acad. Sci. USA 83, 6751-6755.

Babiarz B.S. \& Hathaway, H.J. (1988) Hormonal control of the expression of antibody-defined lactosaminoglycans in the mouse uterus. Biol. Reprod. 39, $699-706$.

Barkley, M.S., Geschwind, I.I. \& Bradford, G.E. (1979) The gestational pattern of estradiol, testosterone and progesterone secretion in selected strains of mice. Biol. Reprod. 20, 733-738.

Brodin, T., Chester, A., Karlsson, K.A., Messeter, L., Zopf, D. \& Lundblad, A. (1987) Monoclonal antibodies that recognize both LeB and LeY antigens. Glycoconjugate J. 4, 399-406.

Chavez, D.J. \& Anderson, T.L. (1985) The glycocalyx of the mouse uterine luminal epithelium during estrus, early pregnancy, the peri-implantation period, and delayed implantation. I. Acquisition of Ricinus communis I binding sites during pregnancy. Biol. Reprod. 32, $1135-1142$.

Chen, H.-T. \& Kabat, E.A. (1985) Immunochemical studies on blood groups. J. biol. Chem. 260, $13208-13217$.

Dutt, A., Tang, J.P. \& Carson, D.D. (1987) Lactosaminoglycans are involved in uterine epithelial cell adhesion in vitro. Devl Biol. 119, 27-37.
Dutt, A., Tang, J.P. \& Carson, D.D. (1988) Estrogen preferentially stimulates lactosaminoglycan-containing oligosaccharide synthesis in mouse uteri. J. biol. Chem. 263, 2270-2279.

Enblad, P., Glimelias, B., Busch, C., Pahlman, L., Pointin, J., Chester, M.A. \& Lundblad, A. (1986) Comparative immunohistochemical demonstration of fucosylated carbohydrate antigens and CEA in adenomas and carcinomas of the rectum and rectosigmoid. Anticancer Res. 6, 139-146.

Farach, M.C., Tang, J.P., Decker, G.L. \& Carson, D.D. (1987) Heparin/Heparan sulfate is involved in attachment and spreading of mouse embryos in vitro. Devl Biol. 123, 401-410.

Finn, C.A. \& Martin, L. (1974) The control of implantation. J. Reprod. Fert. 39, 195-206.

Fishel, S.B. \& Surani, M.A.H. (1980) Evidence for the synthesis and release of a glycoprotein by mouse blastocysts. J. Reprod. Fert. 59, 181-185.

Fox, N., Damjanov, I., Martinez-Hernandez, A., Knowles, B.B. \& Solter, D. (1981) Immunohistochemical localization of the early embryonic antigen (SSEA-1) in postimplantation mouse embryos and fetal and adult tissue. Devl Biol. 83, 391-398.

Gidley-Baird, A.A., O'Neill, C., Sinosich, M.J., Porter, R.N., Pike, I.L. \& Saunders, D.M. (1986) Failure of implantation in human in vitro fertilization and embryo transfer patients; the effect of altered progesterone/estrogen ratios in humans and mice. Fert. Steril. 45, 69-74.

Kennedy, T.G. (1983) Embryonic signals and the initiation of blastocyst implantation. Aust. J. biol. Sci. 36, 531-543.

Kimber, S.J., Lindenberg, S. \& Lundblad, A. (1988) Distribution of some Gal $\beta$-1-3(4) GlcNAc related carbohydrate antigens on the mouse uterine epithelium in relation to the peri-implantational period. J. Reprod. Immunol 12, 297-313. 
Kuivanen, P.C. \& Desombre, E.R. (1985) The effect of sequential administration of $17 \beta$-estradiol on the synthesis and secretion of specific proteins in the immature rat uterus. J. Steroid Biochem. 22, 439-451.

Leroy, F. (1982) Receptivite nidatoire de l'endometre. Rev. Med. Brux. 3, 301-304.

Lindenberg, S., Sundberg, K., Kimber, S.J. \& Lundblad, A. (1988) The milk oligosaccharide, lacto-Nfucopentaose I, inhibits attachment of mouse blastocysts on endometrial monolayers. J. Reprod. Fert. 83, $149-158$.

Lyon, M.F. \& Meredith, R. (1966) Autosomal translocation causing male sterility and viable aneuploidy in the mouse. Cytogenetics 5, 335-354.

McCormack, J.T. \& Greenwald, G.S. (1974) Progesterone and oestradiol-17 concentrations in the peripheral plasma during pregnancy in the mouse. $J$. Endocr. 62, 101-107.

McLaren, A. \& Michie, D. (1956) Studies on the transfer of fertilized mouse eggs to uterine foster-mothers. I. Factors affecting the implantation and survival of native and transferred eggs. J. exp. Biol. 33, 394-4I6.

Messeter, L., Brodin, T., Chester, M.A., Karlsson, K.A., Zopf, D. \& Lundblad, A. (1984) Immunochemical characterization of a monoclonal anti-Leb blood group reagent. Vox Sang. 46, 66-74.

Morris, J.E., Potter, S.W. \& Gaza-Bulseco, G. (1988) Estradiol induces an accumulation of free heparan sulfate glycosaminoglycan chains in uterine epithelium. Endocrinology 122, 242-253.

Muramatsu, T., Gachelin, G., Nicolas, J.F., Condamine, H., Jakob, H. \& Jacob, F. (1978) Carbohydrate structure and cell differentiation: unique properties of fucosyl-glycopeptides isolated from embryonal carcinoma cells. Proc. natn. Acad. Sci, USA 75, 2315-2319.

Muramatsu, H., Ishihara, H., Miyauchi, T., Gachelin, G., Fujisaki, T., Tejima, S. \& Muramatsu, T. (1983) Glycoproteins-bound large carbohydrates of early embryonic cells: structural characteristics of the glycan isolated from $\mathrm{F} 9$ embryonal carcinoma cells. $J$. Biochem. 94, 284-296.

Nieder, G.L., Weitlauf, H.M. \& Suda-Hartmann, M. (1987) Synthesis and secretion of stage-specific proteins by periimplantation mouse embryos. Biol. Reprod. 36, 687-699.

Pennington, J.E., Rastan, S., Roelcke, D. \& Feizi T. (1985) Saccharide structures of the mouse embryo during the first eight days of development. $J$. Embryol. exp. Morph. 90, 335-361.

Pentecost, B.T. \& Teng, C.T. (1987) Lactotransferrin is the major estrogen inducible protein of mouse uterine secretions. J. biol. Chem. 262, 10134-10139.

Psychoyos, A. (1976) Hormonal control of uterine receptivity for nidation. J. Reprod. Fert. 25, 17-28.

Psychoyos, A. (1986) Uterine receptivity for nidation. Annls N.Y. Acad. Sci. 476, 36-42.

Psychoyos, A. \& Casimiri, V. (1980) Factors involved in uterine receptiveness and refractoriness. Prog. Reprod. Biol. 7, 143-157.

Solter, D. \& Knowles, B.B. (1978) Monoclonal antibodies definding a stage specific mouse embryonic antigen (SSEA 1). Proc. natn. Acad. Sci. USA 75, 5565-5569.

Sutherland, A.E., Calarco, P.G. \& Damsky, C.H. (1988) Expression and function of cell surface extracellular matrix receptors in mouse blastocyst attachment and outgrowth. J. Cell. Biol. 106, 1331-1348.

Takeda, A., Takahashi, N. \& Shimizu, S. (1988) Identification and characterization of an estrogen inducible glycoprotein (uterine secretory protein-1) synthesized and secreted by rat uterine epithelium cells. Endocrinology 122, 105-113.

Teng, C.T., Walker, M.P., Bhattacharyya, S.N., Klapper, D.G., DiAugustine, R.P. \& McLachlan, J.A. (1986) Purification and properties of an oestrogen-stimulated mouse uterine glycoprotein (approx. $70 \mathrm{kD}$ ). Biochem. J. 240, 413-422.

Received 5 May 1989 